\title{
Working During the Pandemic: The Effect of Work Passion on Happiness at Work While Working at Home During the Covid-19 Pandemic
}

\author{
Ilham Medal Junjunan* \\ Department of Psychology, Universitas Informatika dan Bisnis Indonesia, Bandung, 40283, Indonesia. \\ *Corresponding author. Email: ilhammedal@unibi.ac.id
}

\begin{abstract}
This study aims to identify the influence of a person's individual factors, in this case work passion, which consists of harmonious work passion and obsessive work passion on happiness at work when working from home during the Covid-19 pandemic. This study was conducted on 55 participants consisting of 28 women and 27 men of various ages and various occupations. The results showed that Harmonious work passion has a significant effect, only there is a dimension of job engagement on happiness at work, while obsessive work passion has a significant effect on a person's job engagement and job effect on the variable happiness at work.
\end{abstract}

Keywords: Work passion, passion, harmonious work passion, obsessive work passion, happiness, happiness at work

\section{INTRODUCTION}

The Covid-19 pandemic forces most of the world's population to carry out physical distancing or social distancing. As a result, many daily activities that require social interaction, currently only carried out by telecommuting from individual homes, schools, shops and even offices are required to close and operate telecommuting or online from home, except for companies that do directly. production processes for the necessities of life of many people, and retail that sells daily necessities such as markets and supermarkets. The rest, almost all offices telecommuting from home or what is now better known as work from home or abbreviated as WFH.

Previous research found positive and negative effects of telecommuting, the positive side of telecommuting, according to Duxbury (1992), which can increase job satisfaction and get a work-life balance [1]. Negatively, Pool (1990) states that telecommuting causes a person to experience feelings of social isolation, career isolation, feelings of anxiety about job continuity, and long working hours [2].

In the context of psychology, individual behavior will be influenced by their function or social events or events outside of themselves [3]. In this study, the social function has adjusted to conditions that are currently massive in almost all corners of the world. Namely the Covid-19 pandemic, from an individual perspective the author explores one of the important things in work, namely having a passion for work or what we call work passion. Previous research has found that work passion has a positive relationship with performance [4], job satisfaction [5] and employee wellbeing [6]. Work Passion is the process of internalizing a job into one's identity, and Work passion itself is divided into two types, Harmonious work passion and Obsessive work passion [7]. Harmonious work passion is the passion that a person has when the job he is doing is able to run in harmony with other activities outside of work, while obsessive work passion is a passion for work, where the work is the main focus and cannot run in harmony with other activities outside of work.

Furthermore, in this study, the author will discuss the role of work passion for happiness at work when working telecommuting at home due to the Covid-19 pandemic

\section{LITERATURE REVIEW}

\subsection{Passion}

Passion is a process of internalizing an activity they like into their own identity, so that they willingly invest their time and energy for this activity [7]. Vallerand (2003) added that passion is divided into two types, namely 
obsessive passion and harmonious passion. Obsessive passion arises because there are more external influences, and when someone has an obsessive passion, they cannot control themselves to stop activities they enjoy doing . so that it can create conflicts with other activities in themselves. Meanwhile, harmonious passion arises from within or is internal in nature, and will be in harmony with other things outside of the activities that they enjoy doing, so if someone has a harmonious work passion it will be easy for them to stop doing the activities they enjoy doing.

\subsection{Work Passion}

In line with the passion theory, work passion is where someone likes their job and is internalized by life and themselves [7]. Work Passion itself is divided into two, Obsessive work passion, where a person internalizes their work because of many external factors, and it is difficult for them to get away from work activities, and Harmonious Passion, where their work is internalized internally or voluntarily, does not interfere with other things in life so as not to cause conflict in life.

Work passion is found to have a major influence on one's work, work passion has an influence on performance, especially passion in the form of harmonious work passion has a positive effect on performance, while obsessive work passion actually has a negative effect on performance. Work Passion also has a positive influence on one's wellbeing [8], Besides that, Ashtakova (2015) found that harmonious work passion which is not too high has a significant effect on organizational citizenship behavior, while obsessive work Passions must be strengthened by collectivity values in order to have a significant influence on organizational citizenship behavior [4]. Even when we talk about retirement, work passion has a significant role; Houlfort (2015) found that work passion has a positive and negative influence on the readiness to transition to retirement [9]. Harmonious work passion was found to have a positive effect on the readiness for the transition to retirement, on the other hand, obsessive work passion has a negative effect on the readiness for the transition to retirement. Work passion also has an influence as a moderator on empowering leaders on performance, harmonious work passion has been found to have a positive influence in strengthening the relationship between empowering leaders and performance, while obsessive work performance has a negative effect in strengthening the relationship between empowering leaders and performance [10]. In addition to having a direct effect, increased employee motivation which is influenced by the strengthening of the climate of cooperation can also be stronger when employees have a work passion in their work [11]. Based on the studies that have been described, work passion is considered to have an important role in one's work. It's just that not many have explained how work passion affects work when working remotely or telecommuting, this is the reason for researchers to raise the topic of work passion as an interesting thing that should be researched when working remotely or telecommuting or work from home.

\subsection{Work Passion Happiness at work}

Happiness is one of the positive emotions that an individual has. Happiness at work is considered to lead to positive experiences at work through pleasant judgment through positive attitude and pleasant experiences through positive emotions, moods, and positive feelings. Happiness at work is broad, there are several things that can describe happiness at work such as job satisfaction, job engagement, organizational commitment, job involvement, thriving and vigor, flow and intrinsic motivation, and affect at work. Happiness is generally influenced by three things, the environment, the individual's internal, external interactions, and the behavior of an individual's initiative. When someone works, the work environment greatly affects their happiness at work. Bosses, co-workers, subordinates, and the job itself have a share in influencing a person's happiness at work. At the organizational level, workers' trust in the employer as well as the organizational culture itself has a big contribution to worker's happiness. At the level of work, what make someone happy are the characteristics of the job itself, how the job provides new challenges, is complex, has autonomy, provides feedback and is interesting [12]. The next level that affects happiness at work is the event level, where when an unexpected event occurs at work, either positive or negative. Happiness at work arises when workers face these unexpected events positively and receive positive praise, feedback or recognition from their environment. This is in line with Herzberg's motivation theory, where he states that someone will feel satisfied at work not because of the salary or income he gets but because of internal rewards, in the form of praise, recognition, and positive feedback from superiors and colleagues. Happiness at work, added on ref [13]. if it is concluded, it will consist of three dimensions, namely job engagement, job satisfaction, and job affect. Happiness at work is important in work, previous research found that the dimensions of happiness at work have positive influence on job performance, except for the dimensions of job satisfaction [14], and also on organizational citizenship behavior [15]. Happiness at work itself is influenced by many factors such as Emotional Labor [16], transformational leaders [17], and Altruistic Leader [18]. Based on previous research, researchers wanted to know how work passion affects happiness at work when doing work from home or telecommuting.

\subsection{Hypothesis}

Based on the discussion of the variable dimensions of work passion and happiness at work above, this study has nine hypotheses.

H1: Passion in general has a significant effect on job engagement 
H2: Harmonious work passion has a significant effect on job engagement

H3: Obsessive work passion has a significant effect on job engagement

H4: Passion in general has a significant effect on job satisfaction

H5: Harmonious work passion has a significant effect on job satisfaction

H6: Obsessive work passion has a significant effect on job satisfaction

H7: Passion in general has a significant effect on job affect

H8: Harmonious work passion has a significant effect on job affect

H9: Obsessive work passion has a significant effect on job affect

\section{METHODOLOGY}

This research was conducted in Bandung Indonesia, using an online questionnaire through the Google Form platform. There were 55 participants in this study consisting of 28 women and 27 men, aged from 23 to 58 years, had a minimum high school education level who was individuals who were still actively working, and had or were still undergoing WFH or telecommuting during the Covid-19 pandemic. To measure Work Passion, researchers used the Work Passion Scale by Vallerand (2008) which was adapted into Indonesian, with reliability in this study having an alpha coefficient of 0.816 [7]. To measure Happiness at Work, researchers used the Happiness at Work Scale by Griffin (2007) which has also been adapted into Indonesian and adjusted to the context of the Covid-19 Pandemic, the Happiness at Work scale in this study has reliability with an alpha coefficient of alpha 0.953 [19].

\section{RESULT}

Based on linear regression analysis using IBM Statistic SPSS 25, it was found that the dimension of passion in general does not have a significant effect on the dimension of job engagement on happiness at work with a significance of sig $=.60$, while harmonious work passion has a significant influence on the dimension of job engagement with significance sig $=.47$. When viewed from Obsessive work passion, it turns out that OWP has a significant effect on the dimensions of job engagement on the happiness at work variable with a significance of $\operatorname{sig}=0.31$.

For the job satisfaction dimension of the happiness at work variable, it was found that when working at home, both passion in general, harmonious work passion and obsessive work passion did not have a significant effect on job satisfaction with a significance of $\operatorname{sig}=.695$ for passion in general, the significance of sig $=.126$ for harmonious work passion and significance sig $=.345$ for obsessive work passion.

Furthermore, seen from the relationship between work passion and the dimension of job effect on the happiness at work variable, it was found that passion in general had no significant effect on job affect, with a sig: .159 significance. Harmonious passion was also found to have no significant effect on job affect, with a sig: .75 significance. However, contrary to that Obsessive work passion has a significant effect on job affect with significance, sig: .035. Details can be seen in Table 1

Table 1 Regression Coefficient on work passion and happiness at work

\begin{tabular}{llll}
\hline Sig & $\begin{array}{l}\text { Job } \\
\text { Engagement }\end{array}$ & $\begin{array}{l}\text { Job } \\
\text { satisfaction }\end{array}$ & $\begin{array}{l}\text { Job } \\
\text { Affect }\end{array}$ \\
\hline General Passion & .060 & .695 & .1559 \\
$\begin{array}{l}\text { Harmonious } \\
\text { work passion }\end{array}$ & .047 & .126 & .075 \\
$\begin{array}{l}\text { Obsessive work } \\
\text { passion }\end{array}$ & .031 & .345 & .035 \\
\hline
\end{tabular}

\section{DISCUSSION}

Even though this study has described the relationship between work passion and happiness at work, it would be better if you consider alternative variables that might affect the relationship between work passion and happiness at work. Satisfaction was also found not to be significantly influenced by work passion. Maybe a reinforcing variable was needed so that the effect could be clearer. The number of participants in this study was relatively small due to the narrow data collection time. On other occasions, it may be necessary to conduct a repeat study with a larger number of participants so that it may be able to produce different conclusions

\section{CONCLUSION}

Based on the results of the analysis above, it can be concluded that hypothesis one is not proven, where work passion in general does not have a significant effect on the dimensions of job engagement on the happiness at work variable, but hypotheses two and three are proven that harmonious work passion and obsessive work passion have a significant effect on Job Engagement Dimensions on Happiness at Work When working WFH or telecommuting. In the dimension of Job satisfaction, hypotheses four, five and six are also not proven where general passion, harmonious passion and obsessive passion have no significant effect on job satisfaction. In the last 
dimension, namely job affect, hypotheses seven and eight are not proven again where passion in general and harmonious work passion do not have a significant effect on job affect, while hypothesis nine is proven that obsessive work passion has a significant effect on job affect.

So in this study there are three accepted hypotheses, namely hypothesis two, hypothesis three and hypothesis Nine. So if it is concluded, in this study, passion in general does not have a significant effect on happiness at work so that individuals who have a passion for their work without us judging that passion is harmonious or obsessive will not necessarily make the individual happy at work, then if we see harmonious work passion which has a significant effect on happiness at work, especially in the dimension of job engagement, so in this study it was found that when someone has a passion for work in the form of a harmonious work passion, the individual will be happier at work while working at home, where he will be willing to be involved in their work, internalize their job identity into themselves and be able to get motivation from their work itself. This is in line with Valerian's theory of harmonious work passion where a person who has a harmonious work passion will get internal motivation from work and within himself. Finally, obsessive work passion is the most influential thing on happiness at work, especially when working at home. Harmonious work passion has a significant influence, especially on the dimensions of job engagement and job affect, so that someone who has obsessive work passion will feel motivated by his job, feel immersed in his work, feel that he loves his job and maybe even loves the organization he works for. Interestingly, the results of this study indicate that individuals with obsessive work passion when working at home have more positive emotions. When connected with the theory (Vallerand, 2003) where obsessive work passion makes a person unable to separate work from other factors in his life, this does not happen when the individual works telecommuting or works from home. This also supports the statement (Duxbury, 1992) which states that when working telecommuting, it will reduce work stress and increase work-life balance.

\section{REFERENCES}

[1] L. E. Duxbury, C. A. Higgins, S. Mills. After-hours telecommuting and work-family conflict: A comparative analysis. Information Systems Research, 3 (2) (1992) 173-190. DOI: https://doi.org/10.1287/isre. 3.2.173

[2] I. De Sola Pool, Technologies without boundaries: On telecommunications in a global age. Cambridge: Harvard University Press, 1990.

[3] K. Lewin. Behavior and development as a function of the total situation. New York: John Wiley \& Sons, 1946.
[4] M. N. Astakhova, G. Porter. Understanding the work passion-performance relationship: The mediating role of organizational identification and moderating role of fit at work. Human Relations, 68 (8) (2015) 13151346. DOI: https://doi.org/10.1177/0018726714555204

[5] S. Thorgren, J. Wincent, C. The influence of passion and work-life thoughts on work satisfaction. Human Resource Development Quarterly, 24 (4) (2013) 469492. DOI : https://doi.org/10.1002/hrdq. 21172

[6] M. A Yukhymenko-Lescroart, G. Sharma. The relationship between faculty members' passion for work and well-being. Journal of Happiness Studies, 20 (3) (2019) 863-881.

[7] J. Vallerand, Robert, Nathalie Houlfort, J. Fores. Passion at work Emerging perspectives on values in organizations. New York: IAP, 2003

[8] F. L. Philippe, R. J. Vallerand, G. L. Lavigne. Passion does make a difference in people's lives: A look at well-being in passionate and non-passionate individuals. Applied Psychology: Health and WellBeing, 1 (1) (2009) 3-22. DOI: https://doi.org/10.1111/ j.1758-0854.2008.01003.x

[9] N. Houlfort, C. Fernet, R. J. Vallerand, A. Laframboise, F Guay, R. Koestner, (2015). The role of passion for work and need satisfaction in psychological adjustment to retirement. Journal of Vocational Behavior, 88 (2015) 84-94. DOI : https://doi.org/10.10 16/j.jvb.2015.02.005

[10] P. Hao, W. He, L. R. Long. Why and when empowering leadership has different effects on employee work performance: The pivotal roles of passion for work and role breadth self-efficacy. Journal of Leadership \& Organizational Studies, 25 (1) (2018) 85-100. DOI : https://doi.org/10.1177/15480518177 07517

[11] V. T. Ho, D. T. Kong, C. H. Lee, P. Dubreuil, J. Forest. Promoting harmonious work passion among unmotivated employees: A two-nation investigation of the compensatory function of cooperative psychological climate. Journal of Vocational Behavior, 106 (2018) 112-125. DOI : https://doi.org/10.1016/j.jvb. 2018.01.005

[12] J. R Hackman, G. R. Oldham, Development of the job diagnostic survey. Journal of Applied psychology, 60 (2) (1975) 159. DOI : https://doi.org/10.1037/h0076 546

[13] S. Singh, Y. Aggarwal, Happiness at work scale: Construction and psychometric validation of a measure 
using mixed method approach. Journal of Happiness Studies, 19 (5) (2018) 1439-1463.

[14] K. Adnan Bataineh. Impact of work-life balance, happiness at work, on employee performance, International Business Research, 12 (2) (2019) 99-112. DOI: https://doi.org/10.5539/ibr.v12n2p99

[15] A. Salas-Vallina, A. López-Cabrales, J. Alegre, R. Fernández. On the road to happiness at work (HAW). Personnel Review. New York: Emerald Publishing Limited. 46 (2) (2017) 314-338. DOI: https://doi.org/10.1108/PR-06-2015-0186

[16] E. J. Ju, E, Y. C. Kwon, M. H. Nam. Influence of clinical nurses' work environment and emotional labor on happiness index. Journal of Korean academy of nursing administration, 21 (2) (2015) 212-222. DOI : https://doi.org/10.11111/jkana.2015.21.2.212

[17] A. Salas-Vallina, J. Alegre, R. Fernandez. Happiness at work and organisational citizenship behaviour. International Journal of Manpower. 38 (3) (2017) 470-488. DOI: https://doi.org/10.1108/IJM-102015-0163

[18] A. Salas-Vallina, J. Alegre, Unselfish leaders? Understanding the role of altruistic leadership and organizational learning on happiness at work (HAW). Leadership \& Organization Development Journal. 39 (5) (2019) 633-649. DOI: https://doi.org/

10.1108/LODJ-11-2017-0345

[19] J. Griffin. What do happiness studies study? Journal of Happiness Studies, 8 (1) (2007) 139-148. 